\title{
Um processo metafórico de Dom Casmurro
}

\section{Preliminares}

Poucos duvidariam, entre os admiradores do estilo de Machado de Assis, que Dom Casmurro ${ }^{1}$ representa, do ângulo da linguagem figurada, um dos indiscutíveis sucessos da ficção machadiana. Basta lembrar, por exemplo, que ai se encontra a metáfora talvez mais conhecida do escritor —"olhos de ressaca"-, aplicável ao olhar absorvente da menina e môça Capitu, cuja fôrça, à maneira de "um fluido misterioso e enérgico", "arrastava para dentro, como a vaga que se retira da praia, nos dias de ressaca". 2 A esta metáfora, desenvolvida ao longo do livro num vaivém de onda marinha, poder-se-ia acrescentar inúmeras outras, ñão necessàriamente menos expressivas, inclusive aquelas de calculada ironia, a exemplo das que pontilham, a cada passo, a frase superlativa e pomposa do agregado José Dias. ${ }^{3}$

O próprio "casmurro" do título, aqui empregado no sentido "que lhe pôs o vulgo de homem calado e metido consigo", a leitura da obra confirma tratar-se de vocábulo extremamente apropriado ao personagem

1 Machado de Assis, Dom Casmurro, in Obra Completa, Rio de Janeiro, Editôra José Aguilar Ltda., 1959, vol. I (Romance). Dado que os capítulos do romance levam títulas descritivos, a referência será feita a êstes, e não ao número da página.

2 Capítulo XXXII "Olhos de ressaca".

$3 \mathrm{O}$ entusiasmo de José Dias pela metáfora ôca é particularmente ironizado no capítulo LXI, "A vaca de Homero," quando o agregado entra a falar, mais de uma vez, nos "santos óleos da teologia." Mas, não esqueçamos, o que de fato singulariza êste personagem é o uso incontrolável do superlativo, embora the saia dos lábios, curiosamente, umas das frases mais sintéticas da narrativa: "Ar é vida." (capítulo CXLIII, "O último superlativo.") Seria oportuno salientar, de passagem, que o romancista, mesmo lhe satirizando os modos de expressão, deixa transparecer um excepcional carinho por José Dias, a ponto de talvez invalidar a repisada teoria de um Machado pessimista. 
em questão. ${ }^{4}$ Enfim, se aprofundássemos um pouco mais, veríamos que até a natureza, quando o exige a circunstância dramática, tranforma-se em Dom Casmurro --ao inverso do que ocorre nos primeiros livros do romanticista ${ }^{5}$ - num correlativo simbólico da narrativa, justificando o surgimento da paisagem não já pictórica, senão psicológica, extensão da geografia moral dos caracteres. ${ }^{6}$

Essas observações esquemáticas, frisando que o descritivo se impõe, neste romance de Machado, antes de tudo por uma caprichosa e profunda manipulação da linguagem, adquiritão talvez maior sentido se ajuntarmos, aos exemplos acima, o de um curioso e sobretudo irônico processo metafórico que se desenvolve entre os capítulos XXXV e XXXVII da narrativa, ligado à caracterização de um dos traços da psicología de Bentinho Santiago $\longrightarrow$ nosso Dom Casmurro. Em benefício do leitor não familiarizado com a obra, resumamos e ilustremos, em poucas palavras, êsse rasgo singular do personagem machadeano, e a cuja análise itia o romancista dedicar, valendo-se das possibilidades da metáfora, uma perícia e uma malícia fora do comum.

Ao contrário da sua namorada e futura esposa Capitu, Bentinho salienta-se desde menino por um temperamento tímido $e$ indeciso, oscilando entre o pensar e o agir, entre a vontade de poder e a impotência da vontade. Eram ainda ambos criançolas quando Capitu, num rasgo

4 Explicando aos leitores o título do romance, diz o narrador: "Não consultes dicionários. Casmurro não está aqui no sentido que eles lhe dão, mas no que the pôs o vulgo de homem calado e metido consigo." (capítulo I, "Do título") Helen Caldwell, num livro çue ainda não teve no Brasil, a divulgação que merece, faz a propósito da explicação do narrador um comentário digno de nota: "But what if we consult our dictionaries? The definition he did not want us to see is this: 'an obstinate, moodily stubborn, wrong-beaded man.' Perhaps we will decide that this older, standard definition fits Santiago better than the one he offers." Helen Caldwell, The Brazilian Otbello of Macbodo de Assis, Berkeley and Los Angeles, The University of California Press, 1960, p. 2.

5 Sôbre a evolução do tratamento da paisagem, em Machado, ver, de Eugênio Gomes "Machado de Assis e a Natureza," in Machado de Assis, Rio de Janeiro, Livraria S. José, 1958.

$6 \hat{\mathrm{E}}$ a caso, entre muitos outros, da pungente descrição do quintal da casa de Matacavalos, em que a natureza desconhece e desconcerta o já confuso narrador com se the apresentar indiferente e sobretudo criptográfica: "No quintal a aroeira e a pitangueira, o poço, a caçamba velha e o lavadouro, nada sabiam de mim. A casuarina era a mesma que eu deixara ao fundo, mas o tronco, em vez de reto, como outrora, tinha agora um ar de ponto de interrogação; naturalmente pasmava do intruso. Corri os olhos pelo ar, buscando algum pensamento que ali deixasse, e não achei nenhum. Ao contrátio, a ramagem começou a sussurrar alguma cousa que não entendi logo, e parece que era a cantiga das manhãs novas. Ao pé dessa música sonora e jovial, ouvi também o grunhir dos porcos, espécie de troça concentrada e filosófica" (capíitul CXLIV, "Uma per. gunta tardia"). 
de intuição muito seu, não hesitou em chamar de "medroso" a Bentinho, definindo-lhe significativamente a indole titubeante. ${ }^{7}$ Além do mais, acentue-se que, no decorrer da história, ou pelo menos até quase o desfêcho, nenhuma decisão de vulto é em verdade tomada por Bertinho, sequer a decisão de casar-se com Capitu, pois que o matrimônio obedeceu antes a um imperativo superior -a fôrça do destino, da qual não foi possível escapar. Com efeito, é a voz de uma "fada invisível", ouvida no capítulo C- "Tu serás feliz, Bentinho", voz que parodia, sabemos, a das feiticeiras de Macbetb: "Tu serás rei, Macbeth"-, que, ao fim e ao cabo, empurra Bentinho ao casamento, ocorrido no capítulo CI ("No céu"). Saliente-se, por outro lado, que, a rigor, a decisão de dissolver a sociedades conjugal também não partiu de Bentinho, mas de Capitu, numa cena de fundas implicações dramáticas: "Não, Bentinho, ou conte o resto, para que eu me defenda, se voce acha que tenho defesa, on peço-lhe desde já a nossa separação: não posso mais!"' De qualquer modo, o que vale assinalar, em tôdas essas situações, é que Bentinho se deixa flutuar ao sabor dos acontecimentos, em cuja maré termina sempre engolfado por uma tendência mais ou menos inata -e nisto, repita-se, êle se mostra diametralmente oposto a Capitu- a não agir nem reagir prontamente, e com denôdo, diante das fundamentais solicitações da vida. Nêste particular, o herói de Machado acaba tipificando, esquemàticamente embora, aquêle passivo e emedrontado menino e moço do século xIx brasileiro, estudado em profundidade na sociologia de Gilberto Freyre, que viu na tortuosa psicologia do adolescente da época menos uma perversão genética que o resultado de uma específica estruturs socio-familiar. ${ }^{9}$

\section{O Processo Metafórico}

A fim de sublinhar, ao vivo e com humor, essa atrofia da vontade no comportamento do seu personagem, Machado de Assis recorrerá, em dado momento, e valendo-se da anatomia, a quatro metáforas consecutivas, ligandoas entre si por um raciocínio único e quase não lhes al-

\footnotetext{
7 capítulo XLIII, "Você tem mêdo?"

8 capitulo CXXXVIII, "Capitu que entra".

9 Ver, de Gilberto Freyre, Sobrados e Mucambos (Decadência do Patriarcado Rural e Desenvolvimento do Urbano), Rio de Janeiro, Livraria José Olympio Editôra, 1961. 3a. edição. Consultar especialmente, no Tomo 1, o capítulo III: "O pai e o Filho".
} 
terando a estrutura linguística. Talvez fosse até lícito afirmar que se trata, no fundo, de uma só metáfora, desdobrada em múltiplas facetas para criar a ilusão de variedade.

A primeira etapa do processo vamos encontrá-la no capítulo XXXV, "O protonotário apostólico", quando o padre Cabral, professor de latim de Bentinho, e há pouco agraciado com aquêle título eclesiástico, diz ao aluno, num tom brincalhão mas por igual vaidoso - a vaidade dos títulos, sempre pulverizada pelo romancista-, que êle também poderá vir a ser "o protonotário Santiago". Ora, Bentinho, cuja mãe almeja vê-lo padre em obediência a uma antiga promessa, não deseja de modo algum ingressar no seminário, não só por carecer de vocação, mas por haver descoberto, momentos antes, nos beiços de Capitu, a alegria de ser homem como os demais e de poder participar, de agora em diante, nas delícias de um amor predestinado a casamento (é a matéria dos capitulos XXXIII e XXXIV, intitulados respectivamente "O penteado" $e$ "Sou homem"). Daí que a observação do protonotário, tanto mais comprometedora, aos olhos do moço, porque feita em presença de D. Glória -com efeito, Cabral de certa forma oficializava, conscientemente ou não, a promessa de D. Gloria-, daí que a observação do professor de latim encontre da parte de Bentinho uma violenta e negativa reação:

Se a intenção do meu mestre de latim era ir acostumando ao uso de título com o nome, não sei bem; o que sei é que quando ouvi o meu nome ligado a tal título, deu-me vontade de dizer um desafôro. Mas a vontade aqui foi antes uma idéia, uma idéia sem lingua, que se deixou ficar quieta e muda, tal como daí a pouco outras idéias... Mas essas pedem um capítulo especial. [grifos nossos]

Aquí se inaugura, com "uma idéia sem língua", a fase primeira do processo metafórico em discussão, entendendo-se que a segunda virá, não no mesmo capítulo, senão no "capítulo especial" prometido ao leitor pelo romancista. E para que não decorra nenhum lapso de tempo entre o prometido e o cumprido, Machado apressa-se a resgatar a dívida logo no capitulo seguinte, XXXVI, cujo título, "Idéia sem pernas e idéia sem braços", testemunha que passáramos da língua a outras partes do corpo, e que a caracterização de um irresoluto Bentinho continua em andamento. Por isso, e como seria de esperar, o "capítulo especial" retoma o fio do anterior, com Bentinho deixando a sala de estar, a fa- 
mília, e o protonotário Cabral, par outra vez pensar "na aventura da manhã" -o advento do primeiro beijo:

Deixei-os, a pretexto de brincar, e fui-me outra vez a pensar na aventura de manhã. Era o que melhor podia fazer sem latim, e até com latim. Ao cabo de cinco minutos, lembrou-me ir correndo à casa vizinha, agarrar Capitu, desfazer-lhe as tranças, refazé-las e concluí-las daquela maneira particular, bôca sôbre bôca. É isto, vamos, é isto... Idéia só! idéia sem pernas! As outras pernas não queriam correr nem andar. Muito depois é que saíram vagarosamepte e levaram-me à casa de Capitu. [grifos nossos].

Designada por "idéia sem língua" no capítulo XXXV, a incapacidade de ação do narrador designa-se agora por "idéia sem pernas" $\longrightarrow$ - que significa, está claro, que se a metáfora mudara de grau, num certo sentido não mudara de gênero: o romancista simplesmente recriava sõbre o já criado. E, logo a seguir, no mesmo capítulo, mas em diverso parágrafo, Machado repetirá o processo, lançando no texto a "idéia sem braços", complemento da seriação anterior. É quando, já diante de Capitu, e lembrando-se do primeiro beijo, Bentinho entra a desejar um segundo, que se extingue em puro desejo por lhe faltar o ímpeto de resgatá-lo à namorada:

Fui ter com ela, a perguntei se a mãe havia dito alguma coisa; respondeu-me que não. A bôca com que respondeu era tal que cuido haverme provocado um gesto de aproximação. Certo é que Capitu recuou um pouco.

Era ocasião de pegá-la, puxá-la, beijá-la... Idéia só! idéia sem braços! Os meus ficaram caídos e mortos [grifos nossos].

A esta altura, justificados o título e a razão do "capítulo especial", seria lícito supôr encerrado, de uma vez por tôdas, o ciclo da metáfora anatômica. Não só porque a ênfase, quando é demais, fatiga, senão porque, no caso particular dêste processo, seria fácil e de pouco mérito artístico desdobrá-lo ao infinito, bastando acrescentar à preposição qualquer outra parte da antomia. Assim, por exemplo, ao imaginoso Bentinho poderia ocorrer a idéia de espiar a vizinha Capitu no banheiro, atitude aliás justificável em quem, como êle, andava no alumbramento erótico do primeiro beijo. Em lhe faltando coragem para tanto, teríamos então a "idéia sem olhos", caso o romancista se decidisse a aproveitar, 
sem esfôrço, o caminho iniciado no capítulo XXXV. Machado de Assis, evidentemente, não concebeu no Dom Casmurro nenhuma cena de banheiro, mas tambén não permitiu, em obediencia à sua paixão de "roer o roído", 10 que se esgotasse na "idéia sem braços" a(s) metáfora(s) até então elaborada(s) com tanto amor. De fato, no capitulo seguinte ao "especial", XXXVII, "A alma é cheia de mistérios", vêmolo retomar o processo sem o menor escrúpulo, só que nesta feição engenhosa e admirável, e sempre enfatizando, em Bentinho, a distância que vai da ação a intenção:

Peguei-lhe levemente na mão direita, depois na esquerda, e fiquei assim pasmado e trêtmulo. Era a idéta com mãos. Quis puxar as de Capitu, para obrigá-la a vir atrás delas, mas ainda agora a ação não respondeu à intenção. [grifos nossos].

Já prestes a se transformar em sistema, e a caminho do que poderid resultar, em última análise, num mecânico e fastiento malabarismo lingu*stico, a caracterização da timidez de Bentinho ganhara vida nova com uma simples - mas a simplicidade de Machado é sempre sofisticadamudança de preposição. Adquirira também, além do elemento surprêsa, uma bem maior amplitude psicológica e humorística - tudo isto conseguido ao fim e ao cabo, através de um sábio manipular do repetição enfática, entrevista como preceito de estilo na "filosofia da composição" do narrador: "Há conceitos que se devem incutir na alma do leitor, á fôrça de repetição". ${ }^{11}$

10 Expressão utilizada no capítulo XVII de Dom Casmurro, "Os vermes", e que bem poderia definir, sob múltiplos aspectos, o estilo ruminante de Machado de Assis. Convém não esquecer, nêste particular, o que o romancista já dizia numa crônica de 21 de janeiro de 1889: "Ninguém sabe o que soru quando rumino. Posso dizer, sem mêdo de errar, que rumino muito melhor do que falo. A palestra é uma espécie de peneira, por onde a idéia sai com dificuldade, creio que mais fina, mas muito menos sincera. Ruminando, a idéia fica íntegra e livre. Sou mais profundo ruminando; e mais elevado também". Obra Completa, cit., v. III, p. 539. Recordetse também, a propósito disso tudo, que Machado tartamuderva, o que levou Sylvio Romero, com a sua inteligéncia malvada, a dizer do estilo machadiano que era um "estilo de gago". A opinião de Sylvio defendeu-a criticamente Medeiros e Albuquerque, em carta a Alfredo Pujol, quando êste vinha de proferir a segunda de suas famosas sete conferências sôbre a vida e a obra de Machado. Ver: Alfredo Pujol, Machado de Assis, 2a. ed., Rio de Janeiro, Livraria José Olympio 1934 , p. 345, nota B.

11 capítulo XXXI, "As curiosidades de Capitu". 


\section{3) CoNClusão}

Que ensinamento poder--se-ia obter, em conclusão, desta metáfora em cadeia, que é uma e que são várias, e a qual, anunciada de certo modo nas Memórias Póstumas de Braz Cubas, ${ }^{12}$ baixaria à pena do romancista durante a elaboração de Dom Casmurro?

Dela não extrairíamos; certo, um exemplo de incontroversa originalidade, que a metáfora de natureza anatômica, além de frequente na linguagem do povo -recordemos, entre outras "pernas da mesa", "braço de mar" e "bôca da noite"-, nunca deixou de constar nom de participar, em maior ou menor escala, dos arquivos da literatura. Já em 1619, por exemplo, ao dedicar a sua Vida de Dom Frei Bartolomeu doj Mártires "Ā Câmara c Govêrno da Notável Vila de Viana e a Toda Mais Nobreza Dela", e depois de falar num "desejo sem efeito" e numas "vozes sem obras", o nosso Frei Luis de Sousa, valendo-se da anatomía, referiu-se mais gràficamente a uma "vontade sem braços" -isto é, uma vontade que, idêntica à do nosso Bentinho, quedava interditada entre o querer e o fazer. ${ }^{13}$ Perigoso seria afirmar, naturalmente, que o que em Dom Casmurro fêz-se idéia sem língua nem pernas, sem braços ou até com eles, veio de Frei Luis de Souza a Machado pelos vasos comunicantes da reminiscencia literária. Pois, se é certo que o nosso romancista leu a Vida do Arcebispo, à qual chegou mesmo a reportar-se numa crônica de 24 de janeiro de 1897, ${ }^{14}$ não é menos verdade que também poderia, de seus próprios recursos, ter concebido el estruturado o processo metafórico em discussão. ${ }^{\mathrm{xt}}$

12 De fato, oito anos antes de Dom Casmurro, Machado valera-se da anatomia a fim de personificar a "idéia fixa" da Braz Cubas: "Com efeito, um dia de manhā, estando a passear na chácara, pendurou-se-me uma idéia no trapézio que eu tinha no cérebro. Uma vez pendurada, entrou a bracejar, a pernear, a fazer as mais arrojadas cabriolas de volatim, que é possível crer. Eu deixei-me estar a contemplá-la. Súbito, deu um grande salto, estendeu os braços $e$ as pernas, até tomar a forma de um X: decifra-me ou devoro-te". (Memórias Póstumas de Btaz Cubas, capítulo II, "O emplasto", in Obra Completa, cit.). A título de ilustração, vale dizer que, em Dom Casmurro, e relacionada ao suicídio,-essa mesma "idéia fixa" não tem braços nem pernas, senão asas, as asas de um pássaro agourento: "Um dia -era uma sexta-feira - não pude mais. Certa idéia, que negrejava $\mathrm{cm}$ mim, abriu as asas e entrou a batê-las de uma lado para outro, como fazem as idéias que querem sair" (capítulo CXXXIII, "Uma idéia").

13 Frei Luis de Sousa, Vida de Dom Frei Bartolomeu dos. Mártires, Lisboa, Livraria Sá da Costa, 1946, v. 1, p. 2.

14 Obra Completa, cit., v. 3, p. 776.

15 Num admirável e relativamente recente livro sobre Dom Casmurro, Eugênio Gomes prefere ver nêste gênero de metáfora, a que chama de "personifica- 
Melhor concluir, por conseguinte, insistindo que é na paizão do detalhe e na volúpia da ironia que reside a verdadeira originalidade desta caracterização de Bentinho. Originalidade que, associada a tantas outras, ontorgaria a Dom Casmurro a glória de ser o livro mais lido de Machado do Assis, aquêlo que ainda hoje nos surprende e comove na vitalidade dins seus setenta anos.

\section{Joaquim-Francisco Coelho}

Stanford University

ção a côr de uma possível prata de casa, mas "a eiva do bumour especioso de: Sterne, pelo qual, segundo a conveniência momentânea do processo artístico, as idéias $e$ as sensaçóes se fundem ou marcham separadamente". O Enigma de Capitu, Rio de Janeiro 2 Livraria José Olympio Editora, 1967, p. 31. Nâo seria fortúito acrescentar, porém, que Sterne "personifica" as idéias de seus caracteres por um processo totalmente diverso. Com efeito, não há no Tristram Shandy, nem no $A$ Sentimental Journey, nenhuma idéia como aquelas de Bentinho, em que partes do carpo humano, através do discurso metafórico, são chamadas a ilustrar, gràfica e irônicamente, as sensaçôes do mundo subjetivo. 